\title{
Rescatar la Procuraduría para la Defensa de los Derechos Humanos: defender la institucionalidad
}

\author{
Y esta voz de defensa y denuncia que muchas veces \\ ha sido interesadamente silenciada, distorsionada \\ y calumniada, o ingenuamente incomprendida \\ por algunos aun dentro de nuestras fronteras...
}

(Monseñor Óscar A. Romero, 14 de febrero de 1978.)

A medida que pasa el tiempo, son más y más las personas e instituciones unidas en torno a un reclamo: que Eduardo Peñate Polanco abandone, de una vez por todas, el despacho del procurador para la defensa de los derechos humanos. Desde julio del año pasado no han sido pocas las iniciativas en tal sentido; destacan entre ellas las piezas de correspondencia entregadas a la Asamblea Legislativa solicitando su destitución. Los principales argumentos para ello: las numerosas denuncias sobre su actuación cuando se desempeñó como funcionario judicial, su nulo conocimiento en materia de derechos humanos y - por lógica- el desacertado papel que está realizando en el cargo al cual llegó de forma ilegítima. Sin embargo, hasta la fecha, ese Órgano ha rechazado todas las solicitudes en tal sentido, pues --como era de esperarse-- no está dispuesto a aceptar el craso error que cometió al nombrar irresponsablemente a un personaje tan cuestionado para ocupar la titularidad de un sitio sumamente importante dentro del aparato estatal.

Pero el tiempo siempre da la razón a quien la tiene; solamente hay que luchar para lograrlo. En ese marco, hace unas semanas se sumó a la exigencia de la población la Unión Social Cristiana (USC); este partido se pronunció por la inmediata salida de Peñate y para ello envió, el pasado jueves 8 de abril, una pieza de correspondencia al
Órgano Legislativo. En ese documento se habla de las irregularidades en las que ha incurrido Peñate durante el período que ha pasado ocupando, inmerecidamente, la "magistratura de conciencia"; en concreto se dice que es un sentimiento generalizado, "incluso entre quienes tomaron la decisión, de que el jueves 2 de julio del año recién pasado se incurrió en un error de graves consecuencias para el desarrollo del proceso democrático del país, al elegir procurador de derechos humanos" a Peñate Polanco, no obstante "existir expedientes abiertos en su contra, en la Corte Suprema de Justicia y en la misma Procuraduría, que emitió una resolución condenatoria en su contra por violación a los derechos humanos".

Y continúa el texto así: "Una vez ratificado, gozando del beneficio de la duda, el funcionario dio inicio a una profusa colección de irregularidades, ampliamente publicitadas, en el uso de los vehículos oficiales, despido injusto de empleados, contratación de amigos, asignándoles altos salarios, viajes de placer, manipulación de expedientes, etc.". Eso arrojó como resultado - tal como lo dijo un periódico de circulación nacional- "la ironía del año", pues la "misma Asamblea Legislativa que lo eligió procurador para la defensa de los derechos humanos, votó por él como el personaje que más influencia negativa tuvo durante 1998". La Unión Social Cristiana, para fundamentar su solicitud, re- 
cordó los señalamientos de la procuradora adjunta de la mujer en el momento de su renuncia: "Ignorancia, incompetencia y arbitrariedad inexcusables del titular y sus más cercanos colaboradores". Para colmo, desde su lamentable llegada al despacho del procurador - sostieñe este partido-, Peñate Polanco lo único que há hecho es "pelearse con quien ha podido incluso con sus electores, sus declaraciones públicas tienen un tono de cinismo y matonería que ofende a toda la sociedad, al grado que los países y las instituciones donantes han retirado su apoyo técnico y económico a la institución".

La iniciativa de la Unión Social Cristiana debe interpretarse como el primer paso concreto de los políticos en el camino para tratar de remediar, en parte, el grave desatino que cometieron; sin duda, tamaña falla puede ser superada si el resto de los partidos apoyan la petición de la USC. Porque ahora ya no se trata de los intereses particulares de determinada fracción o de medir entre ellas sus fuerzas; lo que toca hoy es, más bien, rescatar la Procuraduría para la Defensa de los Derechos Humanos (PDDH) por lo que vale y representa: nació como resultado del mayor sacrificio en la historia de nuestro país y por ella se pagó una alta factura de sangre y dolor.

Se debe recordar que el primer acuerdo entre el gobierno salvadoreño encabezado por la Alianza Republicana Nacionalista (ARENA) y el Frente Farabundo para la Liberación Nacional (FMLN), hace más de nueve años, cuando apenas se podían ver, representó una luz al final del largo y doloroso túnel de la guerra; en él quedaron establecidos los cuatro grandes objetivos del proceso negociador que culminaría en Chapultepec, el 16 de enero de 1992, con la firma de la paz. En efecto, el 4 de abril de 1990, las partes se propusieron "terminar el conflicto armado por la vía política al más corto plazo posible, impulsar la democratización del país, garantizar el irrestricto respeto a los derechos humanos y reunificar a la sociedad salvadoreña".

En el intento por alcanzar esas importantes y ansiadas metas, en el marco de un proceso dinamizado por la mediación de Naciones Unidas, fue convenida -entre otras cosas - la creación de una importante figura: la del procurador para la defensa de los derechos humanos, como uno de los pilares básicos para el establecimiento de una convivencia social distinta por estar fundada en el respeto a la dignidad humana y el cumplimiento de los deberes ciudadanos.
La existencia de esta institución no es, pues, algo improvisado o antojadizo; es fruto de la maratónica ronda que, del 4 al 27 de abril de 1991, tuvo lugar en la ciudad de México, a la cual le siguió una importante reforma de los artículos 191, 192 y 194 de nuestra Constitución de la República que la dejó establecida como parte integrante del Ministerio Público. Pero, como ya se dijo, por encima de todo es resultado del sacrificio realizado por el pueblo salvadoreño que puso las víctimas a las que se debe y sobre las cuales se encuentra edificada. Así pues, entendida como el instrumento que posee su titular para cumplir con sus facultades constitucionales, la PDDH fue creada el 20 de febrero de 1992 mediante el decreto legislativo No. 138.

En aquel entonces, observamos con satisfacción y esperanza la forma cómo fue aprobada su Ley Orgánica; sin dudarlo, destacamos el procedimiento de consenso seguido para su elaboración y manifestamos que la instauración de la misma representaba un interesante avance en lo referente a las posibilidades internas para elevar el nivel de respeto a nuestra dignidad. Así, la Procuraduría para la Defensa de los Derechos Humanos quedó definida en el artículo 2 de su normativa como una institución "de carácter permanente e independiente, con personalidad jurídica propia y autonomía administrativa, cuyo objeto será velar por la protección, promoción y educación de los derechos humanos y por la vigencia irrestricta de los mismos".

Pese a algunas fallas de origen, sería bastante difícil argumentar que con la creación de esta institución no se abrieron vastas posibilidades para la población salvadoreña en lo relativo a la promoción y protección interna de sus derechos; un rápido vistazo a sus principales atribuciones lo confirma. Entre ellas se encuentran: investigar casos de oficio o por denuncia, asistir a las presuntas víctimas, promover recursos judiciales o administrativos en la materia, vigilar la situación de las personas privadas de su libertad, practicar las inspecciones necesarias para su labor, supervisar la actuación de la administración pública frente a las personas, promover reformas ante los órganos del Estado, opinar sobre proyectos de ley que afecten el respeto a los derechos humanos, promover y proponer medidas preventivas, formular conclusiones y recomendaciones en público o en privado, elaborar y publicar informes, desarrollar un programa 
permanente de promoción para difundir el conocimiento de los derechos humanos y garantizar su respeto.

Además de todas las anteriores, la Ley de la Procuraduría para la Defensa de los Derechos Humanos faculta a su titular para -entre otras cosas- velar por el cumplimiento de los procedimientos y plazos legales en los recursos que promueva o en las acciones judiciales que se interese, así como por el respeto a las garantías del debido proceso, evitando la incomunicación de las personas detenidas; llevar un registro de éstas y de los centros autorizados para su internamiento; proponer anteproyectos de ley favorables a los derechos humanos y promover la firma, ratificación o adhesión a tratados internacionales; censurar públicamente a los responsables materiales e intelectuales de las violaciones; procurar, cuando la naturaleza del caso lo permita, la conciliación de intereses entre víctimas y responsables de una violación; comunicarse y cooperar con organismos de promoción y defensa de los derechos humanos y con los diversos sectores nacionales.

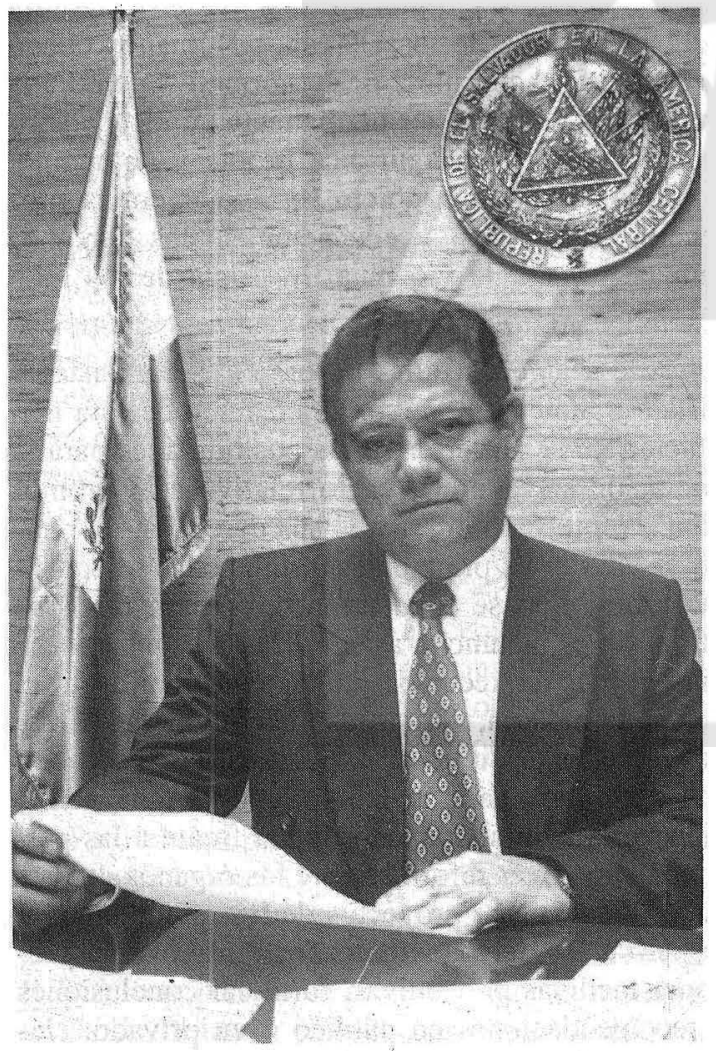

Todas esas atribuciones encuentran sustento en el artículo 10 de la citada Ley, donde se establece que el Procurador "actuará en forma independiente en el ejercicio de su cargo y no podrá ser impedido ni coartado por ninguna autoridad. En el desempeño de sus funciones podrá requerir ayuda, cooperación, informes o dictámenes a los órganos del Estado, autoridad o funcionario civil, militar o de seguridad pública y a cualquier persona, quienes estarán obligados a prestar cooperación con carácter prioritario e inmediato a sus peticiones y recomendaciones". Con todo lo anterior, tenemos suficientes elementos para pensar que las partes al menos en el papel, al momento de firmarlointentaron garantizar una verdadera protección y promoción interna de nuestros derechos; faltaba entonces, únicamente, coherencia entre eso y las acciones concretas para el desarrollo de la institución.

Es precisamente en este punto donde se ubica lo lamentable y condenable de la decisión parlamentaria que introdujo a Peñate Polanco en el despacho del procurador: con ella detuvieron la evolución de la PDDH y la sumieron en un proceso regresivo que dio al traste con las crecientes e importantes expectativas que - dentro y fuera del país- había comenzado a generar entre la gente. No obstante haber permanecido en el sitio durante casi diez meses, hasta ahora no ha demostrado ni siquiera una mínima capacidad para ocupar el lugar; por el contrario, desde su nombramiento no ha desperdiciado un solo momento para evidenciar su incompetencia. Con ello, se le ha hecho un gran daño a una institución fundamental para el desarrollo democrático y el respeto a la dignidad humana en el país; de eso, no hay duda. Pero además de su incapacidad para cumplir con el mandato constitucional del procurador, este individuo -al ser nombrado- se convirtió en el símbolo del desprecio que, salvo algunas muy contadas excepciones, destila la llamada "clase política" contra la institución, los derechos humanos y los acuerdos de paz.

Era de esperar, por sus antecedentes, que Peñate Polanco no pudiera conducir la Procuraduría para la Defensa de los Derechos Humanos; lo que nunca imaginamos es el papel tan ridículo que se ha encargado de andar haciendo en el extranjero durante los foros donde -en su afán por aprovecharse al máximo del cargo - se atreve a participar. Y acá, dentro de nuestro territorio brilla por 
su ausencia. ¿O acaso dijo algo sobre la preocupante situación de la testigo clave en el caso Vilanova? ¿Se pronunció y nos “iluminó" sobre el debate relacionado con las reformas a los códigos Penal y Procesal Penal? ¿Orientó a la sociedad cuando se discutió sobre las modificaciones a la Ley del Menor Infractor, así como cuando se quiso sancionar a los medios de difusión por publicar la identidad de un joven delincuente? ¿Asumió una posición clara y valiente respecto a la denuncia hecha por el padre del muchacho muerto recientemente, durante la visita del presidente estadounidense William Clinton, en un supuesto "accidente de tránsito" del cual se responsabiliza al Grupo de Reacción Policial? Para nada.

Eso sí: en una de sus escasas y siempre poco atinadas declaraciones públicas dentro de El Salvador, cuando acababa de ser nombrado, afirmó que él "vivía los derechos humanos" y agregó que por eso no perdería tiempo participando en eventos. Quizás por la manera desarticulada e incoherente mediante la cual intenta expresarse, no se entendió bien lo que dijo. Pensamos que - tal como lo demuestra la realidad- lo que seguramente debió decir era que el viviría durante tres años $\mathrm{DE}$ los derechos humanos y que no se dedicaría a participar en eventos DENTRO DEL PAÍS, pero que no se perdería ninguno fuera de éste.

$\mathrm{Y}$, por lo visto, tan tristemente célebre personaje pensó que fuera de las fronteras nacionales podía mostrar otra imagen. Eso es lo que pretendió el pasado 22 de abril, cuando intervino ante la Comisión de Derechos Humanos de Naciones Unidas, con sede en Ginebra, Suiza. En esa ocasión, trató de presentar ante ese foro la situación de los derechos humanos en El Salvador. Pero su discurso ante el organismo internacional no fue nada extraordinario; por el contrario, lo terminó pidiendo dinero en el lugar menos indicado y de la manera más inoportuna. "Finalmente -leyó Peñate Polanco - expresarles que la inversión que los gobiemos hacen en la PDDH se está manejando con gran seriedad y transparencia en el marco de los objetivos programados". Sobra decir que las cursivas son nuestras y que, tal como ha sido denunciado por algunos países donantes, esta afirmación no tiene nada que ver con la realidad.

Pese a lo anterior, sus publicistas trataron de vender a la opinión pública esa patética intervención como un trascendental acontecimiento, me- diante un campo pagado con nuestros impuestos. La verdad es que el texto que leyó Peñate Polanco fue una de tantas intervenciones que se dieron ese día, igual o peor que las tantas que tuvieron lugar en el mismo salón por parte de organizaciones no gubernamentales y de otro tipo durante más de un mes, entre marzo y abril. Entre ellas, el director del IDHUCA — sin recurrir a los escándalos propios de aquellos que necesitan promocionarse- participó días antes para denunciar la situación de las y los niños desaparecidos en El Salvador durante la guerra, el clima de violencia e inseguridad actual que se vive en el país, y la fragilidad de las instituciones nacionales.

El pretendido "informe" de Peñate Polanco más bien fue una distorsión de la realidad nacional en esta materia. Lo más rescatable del discurso son los aspectos relacionados con los logros institucionales obtenidos, por supuesto, durante la administración de la doctora Victoria Marina Velásquez de Avilés. Mintió cuando afirmó ante la Comisión que durante su gestión ha señalado y denunciado a quienes violan los derechos humanos; eso sólo lo creen quienes lo colocaron en el puesto y los que se han visto beneficiados con su silencio ante estos casos. Asimismo, dijo cosas como la siguiente: "Estamos muy complacidos y apoyamos los esfuerzos actuales del gobierno salvadoreño encaminados a erradicar la pena de muerte en nuestro país"; también afirmó irónicamente que el primero de los objetivos definidos por la Procuraduría para la Defensa de los Derechos Humanos es: "Propiciar espacios de diálogo y comunicación entre las diferentes fuerzas sociales evitando la polarización y generar un nuevo estilo de concertación social". No cabe duda: el papel aguanta con todo.

Según se desprende del texto, el principal problema en nuestro país lo constituyen las violaciones a los derechos económicos, sociales y culturales; en ese ámbito es donde supuestamente desarrollará los mayores esfuerzos. Entonces, nos preguntamos, ¿qué pasa con las y los trabajadores que fueron despedidos por él desde su llegada a la Procuraduría? ¿No constituye eso, acaso, una muestra de violación a los derechos laborales? Mientras Peñate trataba de convencer en el exterior que en El Salvador disfrutamos de una sólida democracia, basada en el respeto a los derechos humanos, dentro del territorio nacional los proble- 
mas en la PDDH continuaban. El mismo día de su intervención ante la Comisión de la ONU precisamente, su jefe del Departamento de Derechos Económicos, Sociales y Culturales - con años de experiencia y conocimientos acumulados- presentaba su renuncia.

El licenciado Antonio Aguilar argumentó que se retiraba de la Procuraduría, debido a que desde la llegada de Peñate Polanco se había bloqueado el trabajo de ese departamento, a través del recorte de los recursos necesarios para el desarrollo de su labor. Hechos como los anteriores desmienten a Peñate Polanco. ¿Con qué cara se presenta, entonces, ante las Naciones Unidas para hablar de derechos humanos, cuando desde la misma institución -a partir de su llegada - se han violado los derechos humanos de su personal? Con la misma que ha escondido ante las críticas reiteradas y cada vez mayores que se le hacen en el país. Por más que traten su equipo de comunicaciones junto a sus “madrinas y padrinos", es una misión imposible el crear una imagen positiva de Peñate Polanco en la Procuraduría para la Defensa de los Derechos $\mathrm{Hu}-$ manos.

Contrario al ejemplo de su antecesora, Peñate Polanco - en menos de un año- se ha encargado de que la institución y, por ende, la sociedad hayan retrocedido en materia de derechos humanos. $\mathrm{Y}$ eso no pasa desapercibido ante la mirada y el interés de la comunidad internacional, la cual se encuentra sumamente preocupada por el destino de un proceso en el que invirtió tanto y que - hasta hace poco- era presentado como un "modelo". Funcionarios de organismos intergubernamentales, miembros de organizaciones no gubernamentales internacionales y otras personas conocedoras de los derechos humanos que lo han en eventos fuera del pais, coinciden en algo: es impresentable. Menudo favor, entonces, el que le ha hecho la Asamblea Legislativa a la imagen de El Salvador metiendo y manteniendo a Peñate en el despacho del $\mathrm{Om}$ budsman.

Por si lo anterior no bastara, en los últimos días nos enteramos de nuevos señalamientos relacionados con su incorrecto proceder, los cuales se agregan a la lista de críticas —abundantes, por cierto- que pesan sobre sus espaldas. El representante de la PDDH en San Miguel, Juan Yánez, lo denunció hace unas semanas. Según este funcionario, Peñate Polanco quiso sustituirlo porque en esa delegación se han recibido alrededor de diez denuncias en su contra; una de ellas, precisamente, es la que se resolvió estableciendo su responsabilidad por violación a uno de los derechos fundamentales de toda persona: el debido proceso legal.

Y cuando todo parecía indicar que el viento soplaba a favor de la destitución, las y los diputados salieron con otra de las suyas. El 16 de abril, la Asamblea Legislativa envió su respuesta a la solicitud de la Corte Suprema de Justicia para que brindara información sobre el nombramiento de Peñate Polanco. La respuesta no debió sorprender a nadie: pretendía ser una justificación de tan desatinada decisión; asimismo, nadie debe haber quedado satisfecho y mucho menos convencido con tan pobres razones: los llamados "padres de la Patria" -quién sabe por qué, sobre todo en El Salvador- dijeron que Peñate conocía sobre derechos humanos por haber sido funcionario judicial; de ello, concluían automáticamente que "impartía justicia". Por olvido o intencionalmente, no sabemos, pero el caso es que no consideraron que las múltiples denuncias contra él son producto de su mala actuación como juez y magistrado.

En su afán por defender lo indefendible, el Órgano Legislativo sólo está contribuyendo a complicar aún más la ya de por sí difícil situación en la que se encuentra actualmente la Procuraduría para la Defensa de los Derechos Humanos. Porque, además, Peñate Polanco tiene una enorme capacidad para meterse en problemas. Recordemos que en febrero de este año publicó, en tres periódi$\cos$, un comunicado de página entera acusando a varias personas e instituciones de fraguar un plan con la intención — según él- de dañar la institución.

A la opinión pública, quién sabe con qué recursos, se dirigió afirmando que era víctima de un "ataque artero y sistemático" contra su persona, la dignidad de su familia y la credibilidad de la PDDH. Los responsables de esa "malévola conspiración": el reconocido periodista Mauricio Funes; el padre Rodolfo Cardenal, Vicerrector de la UCA; y Benjamín Cuéllar, Director del IDHUCA; asimismo, señalaba como partícipes a "algunos miembros de FESPAD y la Comisión de los Derechos Humanos de El Salvador". Sus "consideraciones" al respecto, siempre inconexas e incoherentes, se resumen a continuación. 
Una "irrefutable vinculación orgánica e ideológica del señor Funes con la anterior administración de la Procuraduría para la Defensa de los Derechos Humanos, asociada con el ala más radical del sector de izquierda", por un lado; por el otro, argumentaba que la "conspiración orquestada por las personas mencionadas, tenía como única finalidad la de mantener privilegios, principalmente las de tipo económico, personal, situación que había permitido la creación de un feudo que quieren vender a la opinión pública, como un derecho adquirido y patrimonio exclusivo de la izquierda radical".

Apelando a su "trabajo honrado" que — según se lee en el comunicado- "es totalmente ajeno a la arrogancia intelectual y a la fachada de inmaculada moralidad que se pretende enarbolar, y cuya única finalidad es generar beneficios financieros", Peñate Polanco exigió "a Mauricio Funes, Rodolfo Cardenal, Benjamín Cuéllar y a todos aquellos que fraguaron esta infame trama de una doble inquisición moral que violó mis derechos humanos y los de mi familia y atentaron contra la estabilidad de nuestra Institución, se abstengan de continuar con este espectáculo, que ya ha sido comprendido por la opinión pública, habiendo quedado al descubierto de una vez por todas los intereses que lo impulsaban al defender con el corazón una posición que más que moral representa intereses económicos".

Con ello, sus patrocinadores pensaron que callarían a quienes los criticaban y que nadie más se atrevería a cuestionar la decisión de haber nombrado a Peñate Polanco; pero de nuevo se equivocaron: los señalamientos continuaron y en un nivel superior. El director del Instituto de Derechos Humanos de la UCA, presentó el pasado viernes 23 de abril a la Asamblea Legislativa una solicitud de antejuicio en su contra. Las razones: dañar el honor y la reputación del demandante. En su escrito, Cuéllar solicitó a la Comisión de Legislación y Puntos Constitucionales que admitiera la denuncia contra Peñate por el delito de difamación, tipificado en el Código Penal vigente, y que le diera trámite de ley al proceso de antejuicio para establecer que hay lugar a formación de causa. La decisión ahora está en manos de esta Comisión, la cual dirá si acepta o no la petición hecha.
No obstante lo fundamentado de tal solicitud y sin haberla leído seguramente, un representante del partido ARENA se pronunció casi de inmediato contra esta iniciativa -que es simplemente un recurso constitucional que cualquier ciudadano puede utilizar - porque, según él, detrás de ella hay intereses políticos y sectoriales que pretenden desprestigiar al país. No podía esperarse menos de quienes son responsables del nombramiento de Peñate Polanco y que siempre tratan de ligar la crisis de la Procuraduría con otro tipo de intereses. ¿Acaso estarán esperando una señal divina que los obligue, de una vez por todas, a sacar a este señor de la institución?

Es casi seguro que cuando este comentario circule entre el público lector, Peñate Polanco y su "camarilla" ya habrán desocupado el despacho del procurador. Eso es bueno; pero queda la preocupación por la certeza de que - pese a todo lo ocurrido durante y después de la guerra- en El Salvador de hoy, para nuestra desgracia, los que ostentan el poder siguen acostumbrados a ejercerlo de manera autoritaria, caprichosa e impune. De esa forma desnaturalizaron las instituciones del pasado y se están llevando por delante las que fueron creadas o renovadas con los acuerdos de paz. Lo han estado haciendo con la Procuraduría para la Defensa de los Derechos Humanos, ya lo vimos; pero también con el Consejo Nacional de la Judicatura, con el Órgano Judicial y -de consumarse el rumor sobre el posible nombramiento de Mauricio Sandoval, actualmente a cargo de la inteligencia del Estado, como director general del cuerpo- también se van a llevar de encuentro a la Policía Nacional Civil.

En el pasado reciente y doloroso, fue necesaria la presión internacional para frenar un poco la irresponsabilidad de estos sectores; parece ser que ahora, lamentablemente, tendrá que ser igual. Enorme desafío se le presenta a la nueva administración del Órgano Ejecutivo en su afán por presentar otra imagen: armonizar su discurso relativo a una nueva forma de hacer política con las barbaridades que comete su partido y los "satélites" que lo acompañan, dentro o fuera de la Asamblea.

Instituto de Derechos Humanos de la Universidad Centroamericana "José Simeón Cañas" 